\title{
Perbedaan Kualitas Hidup Lansia yang Aktif Mengikuti Posyandu Lansia dengan yang Tidak Aktif Mengikuti Posyandu Lansia di Kelurahan
}

\author{
Salestin Rambu Malairu ${ }^{\text {a }}$, Joko Pitoyo ${ }^{a}$

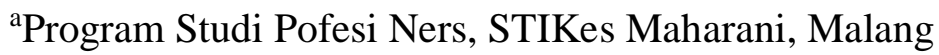 \\ Email Korespondensi: salestinrambu@gmail.com
}

\begin{abstract}
Introduction: Along with the increasing age of the elderly, there are many problems experienced by the elderly, namely about the quality of their lives, so the government has formulated a variety of advanced health care policy to improve the degree of health and quality of the elderly life to reach the happy old age. As a tangible manifestation of the social service of the elderly, the government has proclaimed service in the elderly, namely the Posyandu elderly. This study aims to know quality of life differences between active elderly and inactive elderly in following Posyandu in Mojolangu Village Of Lowokwaru District. Method: This research used Cross Sectional design. Sample were 40 elderlies which were decided using purposive sampling technique. The samples were divided into 2 groups; 20 elderly who were active, and 20 elderly who were inactive. Data analysis used was Chi Square test. Results: The results showed there are $5(25 \%)$ respondents who actively followed Posyandu elderly and had good quality of life. While, $1(5 \%)$ respondents who inactively followed Posyandu elderly had good quality of life. The respondents with a good quality of life had average attendance of 7 times in Posyandu elderly, while inactive elderly had 3 to 4 times. Chi Square test results showed value of $p=$ 0,002. Conclusions: therefore it can be concluded that there is quality of life differences between active elderlies and inactive elderlies who follow Posyandu elderly in Mojolangu Village of Lowokwaru District.
\end{abstract}

Keywords: Quality of Life, Elderly, Health Service Centre

\begin{abstract}
Abstrak
Pendahuluan: Seiring dengan semakin meningkatnya penduduk lansia, terdapat banyak permasalahan yang dialami lansia salah satunya yaitu mengenai kualitas hidup mereka, sehingga pemerintah telah merumuskan berbagai kebijakan pelayanan kesehatan usia lanjut demi meningkatkan derajat kesehatan dan mutu kehidupan lansia untuk mencapai masa tua bahagia. Sebagai wujud nyata pelayanan sosial usia lanjut, pemerintah telah mencanangkan pelayanan pada lansia, yaitu dengan adanya posyandu lansia. Tujuan penelitian ini adalah untuk mengetahui perbedaan kualitas hidup lansia yang aktif mengikuti posyandu lansia dengan yang tidak aktif mengikuti posyandu lansia di Kelurahan Mojolangu Kecamatan Lowokwaru. Metode: Rancangan metode penelitian menggunakan Cross sectional. Sampel penelitian berjumlah 40 orang lansia, pengambilan sampel menggunakan teknik sampling purposive. Sampel dibagi menjadi 2, yaitu 20 sampel lansia yang aktif, dan 20 sampel lansia yang tidak aktif. Analisis data menggunakan uji Chi Square. Hasil: Hasil penelitian menunjukkan 5 (25\%) responden yang aktif ke posyandu memiliki kualitas hidup baik, dan 1 (5\%) responden yang tidak aktif ke posyandu memiliki kualitas hidup baik. Rata-rata kehadiran responden yang aktif mengikuti kegiatan posyandu lansia sebanyak 7 kali pertemuan, sementara lansia yang tidak aktif mengikuti kegiatan posyandu sebanyak 3/4 kali pertemuan. Hasil uji Chi Square di peroleh nilai $\mathrm{p}=0,002$. Kesimpulan: sehingga dapat disimpulkan terdapat perbedaan kualitas hidup lansia yang aktif dengan lansia yang tidak aktif mengikuti posyandu lansia Di Kelurahan Mojolangu Kecamatan Lowokwaru.
\end{abstract}

Malairu, S.R. dkk. Perbedaan Kualitas Hidup Lansia 
Kata kunci: Kualitas Hidup, Lanjut Usia, Posyandu

\section{PENDAHULUAN}

Lanjut usia Lanjut usia (lansia) merupakan suatu kejadian yang pasti dialami secara fisiologis oleh semua orang yang di karuniai umur panjang. Lansia akan mengalami proses penuaan, yang merupakan proses terus menerus (berlanjut) secara alamiah. Menua (menjadi tua) ditandai dengan menghilangnya secara perlahan-lahan kemampuan jaringan untuk memperbaiki diri dan mempertahankan fungsi normalnya, sehingga tidak dapat bertahan terhadap infeksi (Nugroho,2008).

$\begin{array}{rrr}\text { Seiring } & \text { dengan } & \text { semakin } \\ \text { meningkatnya } & \text { penduduk } & \text { lansia, }\end{array}$
pemerintah telah merumuskan berbagai kebijakan pelayanan kesehatan usia lanjut, salah satunya adalah posyandu lansia. Posyandu lansia adalah pos pelayanan terpadu untuk masyarakat lansia di wilayah tertentu yang sudah yang sudah disepakati, yang digerakkan oleh masyarakat untuk mendapatkan pelayanan kesehatan (Erfandi, 2008).

Menurut hasi penelitian yang telah dilakukan (Ismawati, Pebriyanti, Proverawati, 2010), meskipun telah didirikan posyandu lansia ini, namun lansia tersebut tidak memperdulikan dan banyak diantara mereka lebih baik melakukan kegiatan lainnya daripada pergi ke posyandu setiap bulannya. Apabila kegiatan posyandu lansia berjalan lancar maka akan memberi

kemudahan bagi lansia dalam mendapatkan pelayanan kesehatan, sehingga kualitas hidup lansia tetap terjaga dengan baik. Kualitas hidup lansia mencakup kesehatan fisik yang meliputi: kegiatan kehidupan sehari-hari, energi dan kelelahan, mobilitas, rasa sakit dan ketidaknyamanan, tidur dan istirahat, kapasitas kerja. Kondisi psikologi meliputi: bentuk dan tampilan tubuh, perasaan negatif dan positif, penghargaan diri, spiritualitas agama, berpikir, belajar, memori dan konsentrasi. Hubungan sosial meliputi: hubungan pribadi, dukungan sosial, aktivitas seksual. Hubungan dengan lingkungan meliputi: sumber daya keuangan, kebebasan, keamanan, dan kenyamanan fisik, kesehatan dan kepedulian sosial, lingkungan rumah, peluang untuk memperoleh informasi dan keterampilan baru, rekreasi, transportasi.

Menurut Nur Rohmah (2012), hasil penelitian pedahuluan yang diambil peneliti pada bulan April 2010, jumlah lanjut usia di Panti Werdha Hargo Dedali Surabaya ada 41 orang. Hasil pengambilan data awal yang dilakukan peneliti, dari 5 orang lanjut usia di Panti Werdha Hargo Dedali, sebagian besar (80\%) dari mereka mengungkapkan dan mengeluh tentang kehidupannya di masa tua yang sangat susah. Mereka merasa terbatas aktivitasnya, sering sakit, lingkungan kurang bersahabat, dan tidak percaya diri dengan penampilan fisiknya sekarang. Ini menjadi tanda rendahnya kualitas hidup lanjut usia disana karena mereka tidak bisa menikmati masa tuanya

$$
\text { Berdasarkan hasil studi }
$$

pendahuluan yang telah peneliti lakukan di Kelurahan

Mojolangu, Kecamatan Lowokwaru Kota Malang, dari 10 orang lansia yang diwawancara, terdapat 3 orang lansia yang aktif mengikuti posyandu lansia dengan kualitas hidup yang "baik", 2 orang lansia aktif mengikuti posyandu lansia dengan kualiatas hidup yang "sedang", 2 orang lansia jarang mengikuti posyandu lansia dengan kualitas hidup yang "kurang", dan 3 orang lansia tidak aktif mengikuti posyandu lansia dengan kualitas hidup yang "buruk" 
PROFESIONAL HEALTH JOURNAL

Volume 1, No. 2, Juni 2020 (Hal. 65-72)

Available Online at https://www.ojsstikesbanyuwangi.com

\section{METODE}

Jenis penelitian yang digunakan adalah Observasional analitik dengan desain cross sectional. Instrumen yang digunakan dalam penelitian ini, yaitu berupa KMS (Kartu Menuju Sehat) lansia yang dibawa pada setiap kunjungan ke posyandu untuk mengetahui lansia yang aktif dan tidak. Sedangkan untuk mengetahui kualitas hidup lansia menggunakan kuesioner WHOQOL-BREF yang terdiri dari 26 pertanyaan dengan 2 item pertanyaan tentang kualitas hidup. Analisis data menggunakan uji Chi Square.

Penelitian dilakukan pada lansia yang berada di posyandu lansia Centewa yang berada di RW 01, Kelurahan Mojolangu Kecamatan Lowokwaru Malang yang berjumlah 40 orang responden yang memenuhi syarat kriteria inklusi dan eksklusi.

Cara pengambilan sampel pada penelitian ini menggunakan sampling purposive. Sampling purposive adalah suatu teknik penetapan sampel dengan cara memilih sampel di antara populasi sesuai dengan yang dikehendaki peneliti (tujuan/masalah dalam penelitian). (Nursalam, 2008).

Variabel Independen (bebas) dalam penelitian ini adalah lansia yang aktif dan tidak aktif. Sedangkan Variabel Dependen (terikat) dalam penelitian ini adalah kualitas hidup.

Dalam melakukan penelitian ini, peneliti perlu membawa rekomendasi dari Institusinya untuk pihak lain dengan cara mengajukan permohonan ijin kepada Institusi / Lembaga tempat penelitian yang dituju oleh peneliti. Setelah mendapatkan pesetujuan dengan Ethics Committee No.007a/KEPK.SM-EC/VI/2019, barulah peneliti dapat melakukan penelitian

\section{HASIL}

1. Karakteristik responden berdasarkan usia

Responden berdasarkan umur paling banyak adalah usia 60 - 69 tahun dan 70-74 tahun . Responden usia 60 - 69 tahun yang aktif ada 15 orang (37,5\%) dan yang tidak aktif ada 13 orang $(32,5 \%)$, responden umu lebih dari 70 tahun yang aktif ada 13 orang $(32,5 \%)$ dan tidak aktif ada 7 orang $(17,5 \%)$.

2. Karakteristik responden jenis kelamin Responden perempuan yang aktif ada 14 orang (35\%) dan yang tidak aktif ada 15 orang $(37,5 \%)$, responden laki-laki yang aktif ada 15 orang $(37,5 \%)$ dan yang tidak aktif ada 5 orang $(12,5 \%)$.

3. Karakteristik responden berdasarkan pendidikan

Pendidikan responden paling banyak adalah SD yaitu sebanyak 15 orang $(37.5 \%)$.

4. Karakteristik responden berdasarkan pekerjaan

Responden paling banyak tidak bekerja yaitu 18 orang $(45 \%)$.

5. Karakteristik responden berdasarkan perkawinan

Responden paling banyak menikah yaitu 29 orang $(72,5 \%)$. 
PROFESIONAL HEALTH JOURNAL

Volume 1, No. 2, Juni 2020 (Hal. 65-72)

Available Online at https://www.ojsstikesbanyuwangi.com

6. Analisis Bivariat

Tabel 1. Distribusi tingkat kualitas hidup lansia yang aktif mengikuti posyandu lansia di Kelurahan Mojolangu

\begin{tabular}{lcc}
\hline $\begin{array}{l}\text { Kualitas hidup } \\
\text { Lansia aktif }\end{array}$ & $\mathrm{F}$ & $\%$ \\
\hline Baik & 5 & 25,0 \\
Sedang & 14 & 70,0 \\
Kurang & 1 & 5,0 \\
\hline Total & 20 & 100 \\
\hline
\end{tabular}

Berdasarkan Tabel 1 dari data yang diperoleh melalui kuesioner WHOQOLBREF pada responden di Posyandu Lansia RW 01 Kelurahan Mojolangu Kecamatan Lowokaru, menunjukkan bahwa dari 20 responden tingkat sebagian besar yaitu 14 orang (70\%) mempunyai kualitas hidup sedang, kemudian ada 5 orang (25\%) dengan kualitas hidup baik dan hanya ada 1 orang $(5 \%)$ yang kualitas hidup kurang.

Tabel 2. Distribusi tingkat kualitas hidup lansia yang tidak aktif mengikuti posyandu lansia di kelurahan Mojolangu

\begin{tabular}{lcc}
\hline $\begin{array}{l}\text { Kualitas hidup } \\
\text { Lansia aktif }\end{array}$ & F & $\%$ \\
\hline Baik & 1 & 5,0 \\
Sedang & 10 & 50,0 \\
Kurang & 9 & 45,0 \\
\hline Total & 20 & 100 \\
\hline
\end{tabular}

Berdasarkan Tabel 2 dari data yang diperoleh melalui kuesioner WHOQOLBREF pada responden di Posyandu Lansia RW 01 Kelurahan Mojolangu Kecamatan Lowokaru, menunjukkan bahwa dari 20 responden terdapat 10 orang $(50 \%)$ mempunyai kualitas hidup sedang, kemudian ada 1 orang $(5 \%)$ dengan kualitas hidup baik dan terdapat 9 orang $(45 \%)$ yang mempunyai kualitas hidup kurang.
7. Analisis Univariat

Tabel 3. Distribusi perbedaan kualitas hidup lansia yang tidak aktif mengikuti posyandu lansia di kelurahan Mojolangu

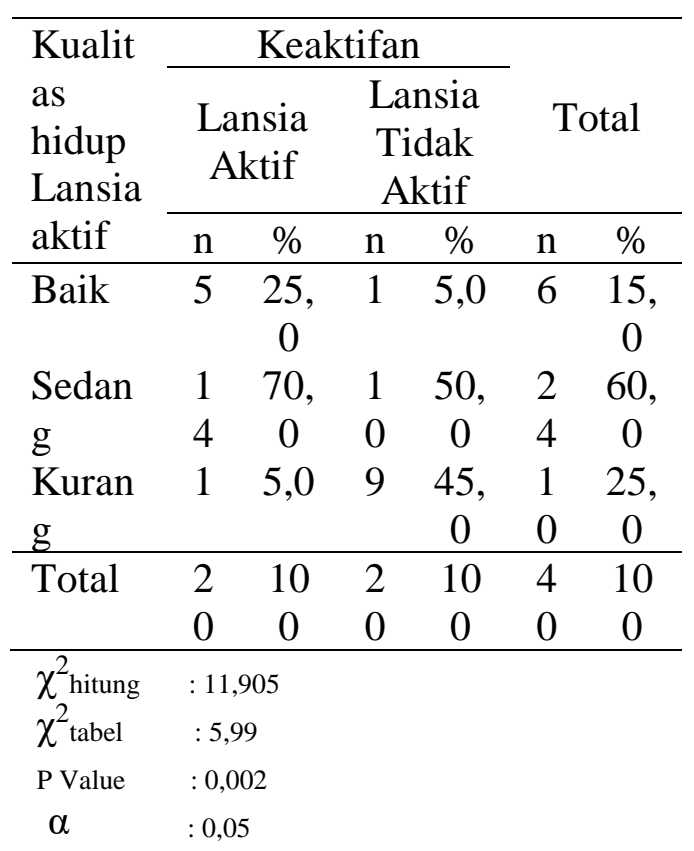

Hasil analisis perbedaan Kualitas Hidup Lansia yang Aktif dan Tidak Aktif Mengikuti Posyandu Lansia di Kelurahan Mojolangu Kecamatan Lowokwaru Tahun 2019 mendapatkan hasil 6 orang (15\%) mempunyai kualitas hidup baik, selanjutkan diketahui ada 24 orang (60\%) mempunyai kuaitas hidup sedang dan ada 10 orang $(25 \%)$ yang mempunyai kualitas hidup kurang.

\section{PEMBAHASAN}

Kesehatan fisik, yaitu keadaan baik, artinya bebas dari sakit pada seluruh badan dan bagian-bagian lainnya. Aliyono, dkk (2012) mengatakan bahwa kesehatan fisik dapat mempengaruhi individu untuk melakukan aktivitas. Aktivitas yang dilakukan individu akan memberikan pengalaman-pengalaman baru yang 
merupakan modal perkembangan ke tahap selanjutnya. Fakta yang ditemukan saat penelitian banyak lansia yang mengeluh kesulitan berdiri terlalu lama, tidak bisa mengangkat beban yang terlalu berat, sering merasa kecapaian dan kelelahan, sering mengalami kram otot. Oleh karena itu, setiap 1 bulan sekali diadakan senam lansia di posyandu lansia Centewa yang dipimpin oleh Kader untuk membantu para lansia meningkatkan daya tahan masa otot dan kekuatan otot, menyehatkan jantung, membuat kualitas tidur lebih baik, dan meningkatkan kebugaran jasmani lansia.

Kesejahteraan psikologis terkait dengan keaadan mental individu. Aliyono, dkk (2012) ,mengatakan keadaan mental mengarah pada mampu atau tidaknya individu menyesuaikan diri terhadap berbagai tuntutan perkembangan sesuai dengan kemampuannya, baik tuntutan dari dalam diri maupun dari luar dirinya. Fakta yang ditemukan saat penelitian beberapa lansia mengatakan sering memiliki perasaan negatif seperti sering cemas, kesepian, tidak menerima tampilan dan bentuk tubuh (seperti gigi ompong, rambut sering rontok), merasa minder. Dengan adanya posyandu lansia yang diadakan tiap bulan diharapkan lansia tidak lagi merasa kesepian dan bisa menerima tampilan dan bentuk tubuh karena bisa bertemu dengan teman sebayanya yang mengalami perubahan seperti itu juga.

\section{Tingkat Kualitas Hidup Lansia yang Tidak Aktif Mengikuti Posyandu Lansia di Kelurahan Mojolangu Kecamatan Lowokwaru}

Berdasarkan penelitian yang dilakukan oleh peneliti, dari 20 orang responden yang tidak aktif mengikuti posyandu lansia, didapatkan tingkat kualitas hidup responden yaitu 10 orang (50\%) mempunyai kualitas hidup sedang, kemudian ada 9 orang (45\%) kualitas hidup kurang dan ada 1 orang (5\%) dengan kualitas hidup baik.
Penjabaran kualitas hidup dalam setiap dimensi untuk lansia yang tidak aktif mengikuti posyandu yakni, dimensi kesehatan fisik adalah kurang 9 orang (45\%), sedang 6 orang (30\%) dan yang baik ada 5 orang (25\%). Kesejahteraan psikologis adalah kurang 7 orang (35\%), sedang 9 orang $(45 \%)$, dan yang baik ada 4 orang (20\%). Hubungan sosial adalah sedang 16 orang $(80 \%)$, baik 3 orang $(15 \%)$, dan yang kurang ada 1 orang $(5 \%)$. Hubungan dengan lingkungan adalah sedang 8 orang $(40 \%)$, baik orang $(5 \%)$, dan yang kurang ada 11 orang (55\%).

Fakta di lapangan menunjukkan bahwa lansia beranggapan bahwa umur yang sudah tua dengan status kesehatan yang menurun tidak ada gunanya untuk mengikuti posyandu lansia, sehingga anggapan lansia dengan status kesehatan yang menurun tersebut sudah ada dalam diri lansia. akibatnya mempengaruhi menurunnya kualitas hidup lansia. Beberapa lansia beranggapan kunjungan ke posyandu bukanlah faktor yang utama. Seringkali kegiatan posyandu yang diadakan setiap bulan sekali pada hari dan tanggal yang ditetapkan bersamaan dengan kegiatan yang dilakukan oleh responden. Karena kegiatan yang bersamaan waktunya maka responden banyak yang tidak aktif. Ada juga lansia yang mengatakan tidak aktif ke posyandu karena mengalami keluhan gerak fisik yang mulai menurun dan berdampak pada menurunnya kualitas hidup. Kualitas hidup responden dapat diketahui dari responden mulai jarang keluar rumah. Dengan berkurangnya interaksi sosial menjadikan responden semakin menutup diri. Bowling (2009) mengatakan bahwa lansia yang mengalami kesulitan dalam melakukan aktivitas fisik akan berdampak pada kualitas hidupnya, terlebih lansia yang sedang mengalami sakit, sehingga di perlukan bantuan orang lain agar kualitas hidupnya tidak semakin menurun. 
Perbedaan Kualitas Hidup Lansia yang Aktif Mengikuti Posyandu Lansia Dengan yang Tidak Aktif Mengikuti Posyandu Lansia di Kelurahan Mojolangu Kecamatan Lowokwaru

Menua (menjadi tua: aging) adalah suatu proses menghilangnya kemampuan secara perlahan-lahan untuk memperbaiki untuk memperbaiki diri atau mengganti diri dan mempertahankan struktur dan fungsi normal sehingga tidak dapat bertahan terhadap infeksi dan memperbaiki kerusakan yang diderita. Menua bukanlah suatu penyakit tetapi merupakan proses berkurangnya daya tahan tubuh dalam menghadapi rangsangan dalam maupun luar tubuh. Akibat adanya rangsangan tersebut dapat mempengaruhi kesehatan fisik lansia yang menyebabkan lansia menjdi tergantung kepada orang lain. Keterbatasan fisik pada lansia tersebut menyebabkan keterbatasan dalam melakukan aktivitas sehingga mempengaruhi tingkat kualitas hidup lansia

Berdasarkan hasil penelitian ini, maka pengetahuan tentang segala hal yang berkaitan dengan kualitas hidup lansia bisa berdampak cukup signifikan, sehingga dengan pendidikan bisa menjadi faktor yang cukup kuat dalam meningkatkan pengetahuan tentang kualitas hidup lansia. Hasil penelitan yang dilakukan peneliti didukung oleh beberapa penelitian. Sebuah penelitian yang dilakukan Fitriani (2018) di Jeneponto menunjukkan hasil yang sama bahwa tingkat pendidikan dengan kualitas hidup lansia berhubungan secara signifikan. Begitu pula penelitian yang dilakukan Supriana (2018) menunjukkan antara tingkat pendidikan dengan tingkat pengetahuan keluarga tentang kualitas hidup lansia ada hubungan yang signifikan. Sehingga latar belakang pendidikan tidak berpengaruh terhadap pengetahuan mereka.

Selain tingkat pendidikan dengan tingkat pengetahuan tentang kualitas hidup lansia, penelitian ini juga menangkap bahwa pekerjaan bisa memberikan dampak pada hal tersebut. Jika seseorang mempunyai pekerjaan yang baik seperti Guru, PNS, dan sejenisnya tentunya memiliki pengetahuan baik tentang kualitas hidup. Namun jika seseorang mempunyai pekerjaan yang rendah seperti Petani, Buruh dan sejenisnya tentunya memiliki pengetahuan kurang tentang kualitas hidup.

Posyandu merupakan wadah berkumpulnya lansia dengan teman sebayanya. Dalam kegiatan posyandu, juga terdapat kegiatan rutin yang dilaksanakan setahun sekali yaitu rekreasi melalui iuran rutin yang tidak memberatkan lansia. Hal tersebut dimkasudkan agar lansia semakin termotivasi untuk mengikuti kegiatan posyandu. Sehingga lansia yang mengikuti posyandu tidak merasa kesepian, mereka juga merasa dihargai, diperhatikan, dan dicintai oleh orang-orang sekitar. Berbeda dengan lansia yang tidak aktif aktif, umunya mereka lebih banyak menarik diri dari pergaulan karena mereka menganggap bahwa dirinya sudah terlalu tua. Padahal hal tersebut justru akan mendatangkan berbagai penyakit. Dalam kegiatan posyandu juga terdapat pemeriksaan status mental. Pemeriksaan status mental ini dilakukan dengan cara memberikan beberapa pertanyaan untuk melatih konsentrasi dan ingatan lansia. Oleh karena itu, kesehatan mental lansia yang mengikuti posyandu akan lebih baik dari pada mereka yang tidak mengikuti posyandu.

Hasil penelitian, diketahui bahwa keberadaan posyandu sangat berdampak positif bagi lansia, dimana kegiatankegiatan yang ada di posyandu sangatlah bermanfaat bagi lansia. Hali ini dibuktikan dengan tingginya tingkat kemandirian lansia yang masih berperan aktif dalam mengikuti kegiatan posyandu. Kegiatan posyandu lansia yang berjalan dengan baik akan memberi kemudahan bagi lansia 
PROFESIONAL HEALTH JOURNAL

Volume 1, No. 2, Juni 2020 (Hal. 65-72)

Available Online at https://www.ojsstikesbanyuwangi.com

dalam mendapatkan pelayanan kesehatatan dasar, sehingga kualitas hidup lansia tetap terjaga dengan baik dan optimal salah satunya dengan memanfaatkan posyandu. Pemanfaatan posyandu lansia dapat dikatakan bermanfaat atau berhasil apabila lansia dapat mengoontrol kesehatannya sendiri khususnya dalam kegiatan aktivitas atau ADL secara mandiri.

Lansia yang aktif ke posyandu lansia secara umum memunyai kualitas hidup sedang yaitu $70 \%$, dan baik $25 \%$, sedangkan lansia yang tidak aktif ke posyandu lansia mempunyai kualitas hidup sedang yaitu $50 \%$, dan kualitas hidup kurang $45 \%$. Hasil analisis statistik penelitian menggunakan Uji Chi Square sehingga diperoleh $\chi^{2}$ hitung sebesar 11,905 sehingga lebih besar dari nilai $\chi_{\text {tabel }}^{2}$ sebesar 5,99 dengan nilai nilai $\mathrm{p}=0,002$ yang berarti untuk nilai $\mathrm{P}$ valuenya $<\alpha$, yaitu dengan $\alpha=0,05$. Hasil analisis ini membuktikan bahwa ada perbedaan yang signifikan Kualitas Hidup Lansia Aktif dan Tidak Aktif Berkujung ke Posyandu Lansia.

\section{KESIMPULAN}

Ada perbedaan yang dibuktikan hasil uji statistik uji Fisher's Exact Test sehingga diperoleh $\chi^{2}$ hitung sebesar 11,905 sehingga lebih besar dari nilai $\chi_{\text {tabel }}^{2}$ sebesar 5,99 dengan nilai nilai $\mathrm{p}=0,002$ yang berarti untuk nilai $\mathrm{P}$ valuenya $<\alpha$, yaitu dengan $\alpha=0,05$. Hasil analisis ini membuktikan bahwa ada perbedaan yang signifikan Kualitas Hidup Lansia Aktif dan Tidak Aktif Berkujung ke Posyandu Lansia di Kelurahan Mojolangu Kecamatan Lowokwaru.

\section{SARAN}

Dengan adanya penelitian ini, diharapkan lansia yang tidak aktif mengikuti kegiatan posyandu lansia, agar bisa aktif berpartisipasi dalam mengikuti Malairu, S.R. dkk. Perbedaan Kualitas Hidup Lansia kegiatan posyandu lansia, karena posyandu lansia sangat bermanfaat bagi kesehatan lansia sehingga dapat mempertahankan kualitas hidupnya.

\section{DAFTAR RUJUKAN}

Aliyono et all. (2012). Studi Deskriptif Kualitas Hidup Buruh Pabrik Rokok $x$ di Surabaya. Jurnal Keperawatan : Volume 1. No 2.

Ariyanti R et al. (2009). Hubungan antara Fungsi Keluarga dengan Kualitas

Hidup Pada Lansia di Dusun GeblaganTamantirto Kasihan Bantul Yogyakarta. Jurnal Keperawatan: Volume 3. No 2.

Azizah, lilik ma'rifatul. (2011). Keperawatan lanjut usia. Edisi pertama.Yogyakarta : Graha Ilmu.

Aviana et al. (2016) Hubungan Pendidikan, Kebiasaan Olahraga, dan Pola Makan Dengan Kualitas Hidup Lansia Di Pusekesmas Wonokromo Surabaya. Vol.4.No.1 Juli 2016:59-69

Bowling. (2009). Quality of Life Among Older People with Poor Functioning. The Influence of Perceived Control Over Life. Jurnal Kesehatan. Oxford University Press on Behalf Of the British Geriatrics Society.

Dahlan, S.M. (2013). Besar Sampel dan Cara Pengambilan Sampel. Jakarta: Salemba Medika

Depkes RI. (2010). Pedoman Puskesmas Santun Lanjut Usia Bagi Petugas Kesehatan. Jakarta: Direktorat Bina Kesehatan Komunitas

Depkes RI. (2010). Pedoman Pembinaan Kesehatan Usia Lanjut Bagi Petugas Kesehatan. Jakarta: Depertemen Kesehatan RI. 
PROFESIONAL HEALTH JOURNAL

Volume 1, No. 2, Juni 2020 (Hal. 65-72) Available Online at https://www.ojsstikesbanyuwangi.com

Depkes RI. (2014). Pedoman Pemantauan dan Penilaian Program Kesehatan Usia Lanjut Bagi Petugas Kesehatan. Jakarta: Bina Kesehatan Masyarakat Departemen Kesehatan.

Ediawati E. (2012). Gambaran Tingkat Kemandirian Dalam Activity Of Daily Living (ADL) dan Resiko Jatuh Pada Lansia di Panti Sosial Tresna Werda Budi Mulia 01 dan 03 Jakarta Timur. Skripsi (diterbitkan). Depok: Universitas Indonesia

Erfandi. (2008). Pengelolaan Posyandu Lansia. Diakses tanggal 17 Mei 2016

Efendi, Ferry \& Makhfud. (2009). Keperawatan Kesehatan Komunitas Teori dan Praktik dalam Keperawatan. Jakarta : Salemba Medika.

Fitrini A \& Agustin H (2018). Hubungan Antara Beban Subjektif dengan Kualitas Hidup pendamping (Caregiver) Pasien Skizofrenia. Fakultas Psikologi, Universitas Islam Sultan Agung: Volume13, No 1, 2018 13-24.

Gureje, Oye. et all. (2008). Determinan of Quality of Life of Elderly Nigerians: result from the Ibadan Study of Ageing.

http://ukpmc.ac.uk/classic/aticlerender.
cgi.accid=PMC2820711 . Tanggal 23 Mei 2010. Jam 10.23 WIB

Hamid A. (2007). Penduduk Lanjut Usia di Indonesia dan Masalah Kesejahteraannya.

http://www.kemsos.go.id . Diunduh 10 November 2015).

Hardywinoto, Setiabudhi. (2009). Panduan Gerontologi. Jakarta: Pustaka Utama

https://www.who.int/substance_abuse/rese arch_tools/en/indonesian_whoqol2004. pdf

Ismawati. Pebriyanti, S. Proverawati, A. (2010). Posyandu dan Desa Siaga panduan untuk Bidan dan Kader. Yogyakart : Nuha Medika

Nugroho, Wayudi . Keperawatan Gerontik dan Geriatrik. Edisi 3. Jakarta : EGC, 2008:76-7.

Nursalam. (2008). Konsep dan Penerapan Metodelogi Penelitian Ilmu Keperawatan Pedoman Skripsi, Tesis dan Instrumen Penelitian Keperawatan. Jakarta: Salemba Medika.

Rohmah. et all. (2012) Kualitas Hidup Lansia. Jurnal Keperawatan: volume 3 , nomor 2 . 